\title{
Enhancement Description
}

National Cancer Institute

\section{Source}

National Cancer Institute. Enhancement Description. NCI Thesaurus. Code C93562.

The textual representation for how an entity is enhanced, either physically or electronically. 